\title{
Desde los fenómenos hacia los conceptos fotográficos. La cámara de Pandora: la fotografía después de la fotografía
}

\author{
Liliana Dávila Lorenzana
}

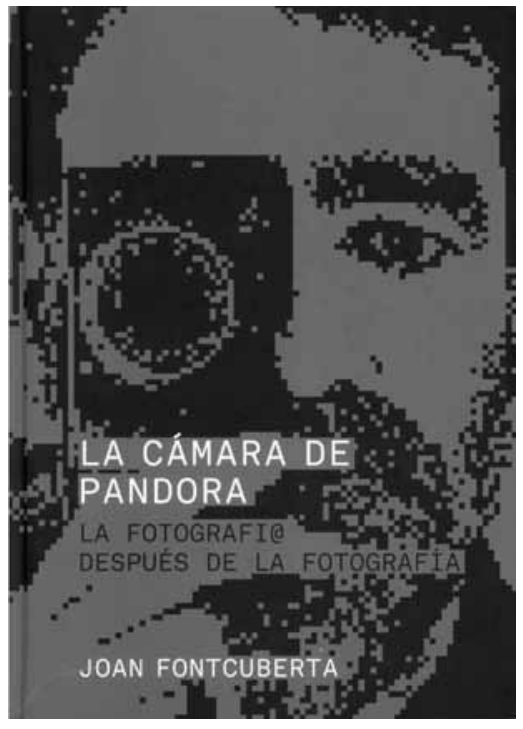

FIGURA 1. Portada del libro La cámara de Pandora: la fotografía después de la fotografía, Joan Fontcuberta, Barcelona, Gustavo Gili, 2010. 
ficciones que permiten estructurar nuestra experiencia de lo real de Žižek (1999), La deconstrucción de Lyotard (1984), La desterritorialización de Deleuze y Guattari (1983), así como El Simulacro de Baudrillard (2005), por mencionar algunos- por los que lleva al lector en un itinerario que abarca la teoría de la fotografía, la semiología, la imagen, la sociedad, la filosofía y el arte contemporáneos.

Los ensayos ofrecen una revisión - y una postura - respecto de los cambios de significado, percepción y uso que están experimentando las representaciones visuales de nuestra sociedad, así como de la materialidad o virtualidad de esta manifestación cultural. Como una idea central, el autor detecta que la fotografía en la época digital se ha transformado llegando a simbolizar conceptos, cuando en la analógica significaba fenómenos. Asimismo, expone como ejemplo que, en lugar de ver las fotografías personales solamente en álbumes o enmarcadas en el ámbito privado, hoy por hoy se encuentran - a pesar de su desmaterialización y, por lo tanto, desterritorializaciónen todas partes y son vistas, a través de los diferentes medios de comunicación, por más personas.

Si en la etapa analógica existía un ritual consistente en preparar a la cámara y al rollo para fotografiar ocasiones específicas de reuniones familiares o con amigos, viajes o cualquier recuerdo especial, en la actualidad ello ya no parece suficiente, sino que se hace necesario registrar cada momento: todo se vuelve fotografiable y mostrable. En esta nueva comunicación de la sociedad (en particular en el caso de los nativos digitales), las fotografías dejan de almacenar sólo recuerdos y se convierten en "exclamaciones de vitalidad, como extensiones de unas vivencias, que se transmiten, se comparten y desaparecen, mental o físicamente" (Fontcuberta 2010:31).

El tema que atañe a la reflexión sobre el patrimonio cultural, Fontcuberta (2010) lo desarrolla a partir de la obra del artista Joachim Schmid
(1955, Alemania $)^{2}$ y la noción de "mal de archivo" de Jacques Derrida (1997). En este caso, con base en la problematización sobre cómo la historia ${ }^{3}$ puede regenerar el presente e incentivar el futuro, se plantean varios cuestionamientos: ¿qué hacer con el patrimonio histórico ${ }^{4}$ ¿Cómo impedir que la historia institucionalizada $^{5}$ restrinja la experiencia del presente y futuro?, ¿Cómo equilibrar el respeto hacia lo antiguo con la libertad de acción para resolver nuestros problemas actuales?, ¿Cómo evitar que la memoria se convierta en un gran cementerio o que, en la obsesión por conservar la materialidad de los objetos, los museos funcionen, tal y como lo han hecho hasta ahora, a modo de mausoleos para glorificar el pasado? (Fontcuberta 2010:177). Su propuesta, así, se dirige hacia la deconstrucción de las imágenes de nuestro pasado y presente para clarificar el espacio entre memoria y desmemoria.

No obstante lo anterior, el tema principal analizado en el trabajo de Founcuberta - tanto en sus fotografías como en sus escritos- es el carácter de documento fiel de verdad, de objetividad y de realidad que era tradicionalmente otorgado a las fotografías y que quedó en duda, con un énfasis particular, aunque no inicial, con el arribo de la imagen digital y su extensiva manipulación. Así, el autor debate esta idea al demostrar que, desde que se inventó, la fotografía ha mentido, no sólo por las propiedades técnicas del aparato y los materiales, sino también por las decisiones del fotógrafo. Asimismo, mediante el replanteamiento de estos

\footnotetext{
2 Particularmente su serie denominada Statics (1995-2005) (World Press 2013).

${ }^{3}$ Aunque el autor use el término historia con minúsculas, el tono de su texto denota que alude a la disciplina.

${ }^{4}$ Fontcuberta (2010:31) se refiere a patrimonio histórico como aquellos bienes que tienen mayor relevancia en su carácter histórico.

${ }^{5}$ Para Fontcuberta (2010), la historia institucionalizada son aquellos discursos que generan el gobierno y las estructuras de poder.
}

argumentos nos lleva a reflexionar si como espectadores o consumidores debemos dudar de la realidad, de la mentira o de la simulación en el que se ha convertido el medio fotográfico o, simplemente, seguir en la creencia - hasta demostrar lo contrario- de su veracidad. Por tanto, Fontcuberta se apropia de la postura de Jean Baudrillard (2005) acerca de cómo la vida contemporánea se ha vuelto un simulacro, en el que la fotografía funge como un ejemplo de tal condición.

Estas características de documentación afectan ante todo, aparte de las disciplinas que usan el medio como herramienta de registro, a la fotografía periodística, género en el que actualmente deben seguirse códigos deontológicos muy rígidos para que la sociedad siga confiando en ellos y la profesión mantenga su fundamento: informar sobre la "realidad" o "verdad" vivida por la comunidad. Sin embargo, persisten varios casos, sin importar el país, en los que el fotógrafo o el editor de los medios de comunicación (revista, noticiario, periódico) han incurrido, con diversas justificaciones, en modificar las imágenes, y es ahí donde, más allá del carácter o las peculiaridades del medio fotográfico, se cimbra el deber ser o la profesión. Por ello es esencial repensar si debemos seguir usando al medio fotográfico como un testigo fiel de documentación o tan sólo revaluar que ningún registro realizado será completamente verdadero, sino una versión de nuestra realidad $\mathrm{O}$, por qué no, una analogía.

Para la comunidad de los conservadores-restauradores, estas discusiones sobre la fotografía conciernen al menos en dos dimensiones, la primera — tal cual acaba de abordarse- como la herramienta de registro utilizada como parte del desarrollo del trabajo, y la segunda como patrimonio cultural. Es necesario, pues, no sólo comprender como objeto de estudio de la disciplina esta herramienta y medio de expresión usado de manera muy activa por la sociedad... no únicamente conocer la técnica, la 
factura o los materiales constituyentes, sino reconocer los significados o los procesos de las representaciones visuales actuales que, por tratarse de algo inmediato, a veces no se las considera parte de nuestra historia, archivo o memoria. Se debe analizar la trasformación de esta re-presentación, si bien como una disciplina externa, es decir, desde la otredad, asimismo como un proceso de nuestra vida cotidiana, social, laboral y económica.

Este libro es recomendable no sólo para aquellos que gustan de la fotografía o la estudian, sino también para quienes desean saber el estado actual de una manifestación cultural integrante de nuestra sociedad e imaginario actual, a la que le damos un uso diario y que ya es parte de nuestros acervos. Su autor provoca más interrogantes que respuestas, lo que, además de llevar a un análisis más profundo acerca de los cambios generados en la sociedad, y en los conceptos de realidad, verdad, ficción, mentira, replantea, por lo tanto, nuevas miradas y maneras de afrontar o acercarnos a nuestros objetos de estudio, no sólo de la fotografía, sino también de las representaciones visuales en general. Conduce, asimismo, a cuestionarse sobre las actividades de documentación basadas en este medio, donde usamos como testigo fiel una imagen en la que realmente creemos, mientras que, por el contrario, a aquella de la que dudamos, o cuyo contenido no nos conviene, la apuntamos como truqueada o photoshopeada.

\section{Referencias}

Barthes, Roland

1981 Camera Lucida: Reflections on Photography, Richard Howard (trad.), Londres, Vintage Books.

Benjamin, Walter

1973 La obra de arte en la época de su reproductibilidad técnica, Jesús Aguirre (trad.), Madrid, Taurus.

Baudrillard, Jean

2005 Cultura y Simulacro, Barcelona, Kairós.

Deleuze, Gilles y Félix Guattari

1983 Anti-Oedipus. Capitalism and Schizophrenia, Robert Hurley, Mark Seem and Helen R. Lane (trad.), Minneapolis, University of Minnesota Press.

Derrida, Jacques 1997 Mal de archivo, Madrid, Trotta.
Fontcuberta, Joan 1997 El Beso de Judas. Fotografía y verdad, Barcelona, Gustavo Gili.

2013 Joan Fontcuberta, documento electrónico disponible en [http://www. fontcuberta.com], consultado en abril de 2013.

Foucault, Michael

2005 Vigilar y castigar, nacimiento de la prisión, México, Siglo Veintiuno Editores.

Hasselblad Foundation 2013 Joan Fontcuberta, Hasselblad Award Winner 2013, documento electrónico disponible en [http://www. hasselbladfoundation.org/hasselbladspristagare-2013], consultado en abril de 2013.

Lyotard Jean-Francois 1984 The Postmodern Condition: A Report on Knowledge, Minneapolis, University of Minnesota Press, World Press

Schmid, Joachim

2013, Statics (1995-2003), documento electrónico disponible en [http:// schmid.wordpress.com/works/19952003-statics/], consultado en agosto de 2013.

Žižek, Slavoj 1999 El acoso de las fantasías, México, Siglo Veintiuno Editores.

\section{Resumen}

Reseña crítica del libro La cámara de Pandora: la fotografía después de la fotografía de Joan Fontcuberta, obra académica en la cual se plasma tanto la visión del artista-fotógrafo como sus argumentos teóricos en relación con la idea del medio fotográfico en su consideración ya sea como documentación veraz, o bien como una estrategia de simulacro de la realidad, con particular énfasis en su empleo en procesos de registro digital de patrimonio cultural.

Palabras clave

Fountcuberta; fotografía; simulacro; Patrimonio Cultural

\section{Abstract}

Critical review of Pandora's Camera: the photograph after the photograph by Joan Fontcuberta, an academic book in which the artist-photographer's vision is expressed as well as his theoretical arguments regarding the idea of the photographic medium as a truthful documentation or as a strategy to simulate reality, with particular emphasis on its use for digitally recording cultural heritage.

\section{Key words}

Fontcuberta; photography; simulation; cultural heritage

Título en inglés: From Phenomena to Photographic Concepts. Pandora's

Camera: The Photograph after the Photograph 